\title{
Hydraulic crimping: application to the assembly of tubular components
}

\author{
Manas Shirgaokar ${ }^{\mathrm{a}}$, Gracious Ngaile ${ }^{\mathrm{a}}$, Taylan Altan ${ }^{\mathrm{a}, *}$, Jang-Horng $\mathrm{Yu}^{\mathrm{b}}$, \\ John Balconi $^{\mathrm{b}}$, Richard Rentfrow ${ }^{\mathrm{b}}$, W.J. Worrell ${ }^{\mathrm{b}}$ \\ a ERC for Net Shape Manufacturing, The Ohio State University, 339 Baker Systems, 1971 Neil Ave., Columbus, OH 43210, USA \\ ${ }^{\mathrm{b}}$ Science and Technology Group, Alliant Ammunition and Powder Company, Radford Army Ammunition Plant, \\ Route 114, P.O. Box 1, Radford, VA 24141-0096, USA
}

\begin{abstract}
The crimping process using a polyurethane tool and hydraulic pressure can be used in the assembly of tubular components. This crimping operation was evaluated with the aid of the finite element method (FEM) and its application to the assembly of tubular components was investigated. The goal was to enhance the performance of the assembly by determining the optimum process and geometrical parameters, such as the material properties of the tube, the interference between the inserted rod and the tube and the rod-tube interface friction. FE simulations were used to evaluate the crimping operation under various process conditions. The crimping process of a double grooved $\mathrm{rod} / \mathrm{bullet}$ with a tubular casing was evaluated as a case study. It was possible to determine the effect of manufacturing tolerances and misalignment between the rod and the casing on the quality of the final assembly in terms of the pullout force.
\end{abstract}

(C) 2003 Elsevier B.V. All rights reserved.

Keywords: Assembly; Crimping; Pullout test; FEM

\section{Introduction}

There is a growing interest in mechanical assembly operations, which do not require additional joining elements, and which can be combined with adhesive joining techniques. The main advantage of these processes is that they do not require any pre- or post-processing since there is no heat or thermal distortion involved [1]. This facilitates the use of pre-painted components for assembly. Another advantage is the absence of chips, dirt or fumes, which provides a safe and hazard-free work environment.

This paper focuses on the crimping of tubular components using soft tools. A literature review shows that little work has been done in the optimization of the process and geometric parameters affecting the crimping process using numeric tools such as the finite element method (FEM). The design of crimping processes for assembling tubular components rely mainly on experimental trial-and-error methods, which prove to be very expensive and time consuming. Process simulation using advanced FEM provides a valuable means

\footnotetext{
* Corresponding author.

E-mail address: altan.1@osu.edu (T. Altan).

URL: http://www.ercnsm.org.
}

for evaluating and optimizing tool and process variables. In this paper, FE simulation is applied to crimping with a soft tool and hydraulic pressure. The assembly process of a bullet is used as a case study.

In the present crimping operation, the rod is press fitted into the tube to a pre-determined depth, and then a hydraulically pressurized rubber crimper pushes the casing into two grooves machined on the rod forming the assembly (Fig. 1). The principle used in crimping with the rubber tool is similar to the popular flex-forming method of sheet metal forming used in the automotive and aerospace industries. In flex-forming a single rigid tool half is combined with a soft tool half in the form of a flexible rubber diaphragm backed hydraulically by a pressurized fluid. The use of a single rigid tool half results in short lead times, low tool cost, fast try-out and easy tool modification to accommodate component-design changes. The flexible rubber diaphragm forms scratch-free parts of complex shape, including undercuts, with different sheet thicknesses in all deformable sheet materials.

The crimp quality is critical to the final performance of the assembly. The quality of the crimping operation is evaluated by a pullout test, which measures the force required to disassemble the grooved rod from the casing. A variation 


\begin{tabular}{|ll}
\hline \multicolumn{2}{l}{ Nomenclature } \\
$E$ & Young's modulus \\
$E_{\mathrm{r}}$ & reduced Young's modulus \\
$H_{\mathrm{B}}$ & Brinell hardness \\
$K$ & material strength coefficient \\
$n$ & strain hardening coefficient \\
& \\
Greek & letters \\
$\bar{\varepsilon}$ & effective strain \\
$\mu$ & crimper-tube interface friction \\
$\nu$ & Poisson's ratio \\
$\bar{\sigma}$ & effective stress
\end{tabular}

in the geometrical properties of the crimp may cause variations in the performance desired from the assembly. Though a failed casing rarely occurs during pullout testing, when it does, it is normally near the crimp.

The principal objectives of the study were to determine:

(i) The material properties of the casing prior to crimping. Since the casing undergoes a series of forming and heat treatment operations, its properties are altered by the time it reaches the crimping stage.

(ii) The optimum range of interference fit between the rod and the casing.

(iii) The alignment between the rod and the casing, which gives the maximum pullout force without damage to the casing in the pullout test.

(iv) The effect of the sealant used during assembly on the quality of the crimp. This effect was considered by using different coefficients of friction $(\mu)$ during crimping and pullout.

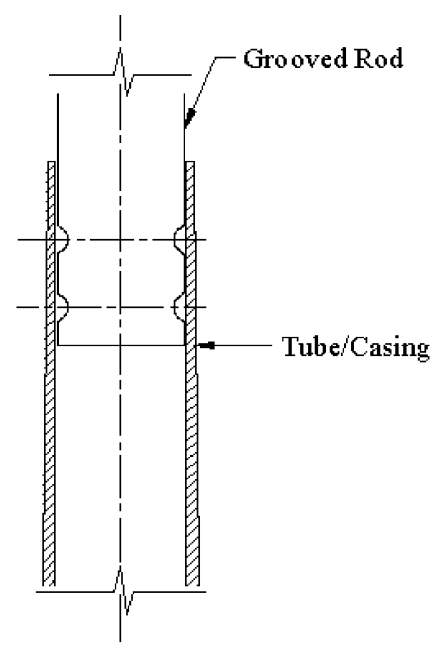

(A) Before crimping.

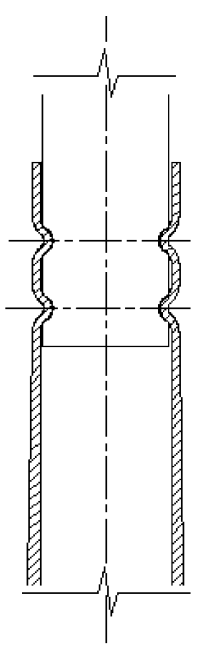

(B) After crimping.
Fig. 1. Rod-casing assembly before and after crimping [2].

\section{Determination of material properties of the casing}

Due to the large number of cold working and heat treatment operations involved, the material properties of the tube/casing change during the manufacturing process.

Therefore, the material property for the casing was approximated from the hardness distribution of the casing along its length using the following expression $[3,4]$ :

$\bar{\sigma}=K \bar{\varepsilon}^{n}=E_{\mathrm{r}}\left(\frac{H}{1.7 E_{\mathrm{r}}}\right)^{1.086}$

where $E_{\mathrm{r}}$ is the reduced Young's modulus defined as $E_{\mathrm{r}}=$ $E /\left(1-v^{2}\right), \bar{\sigma}$ the flow stress defined as $\bar{\sigma}=K \bar{\varepsilon}^{n}$ and $H$ the hardness in ksi. For elastic material data, Young's modulus, $E$, and Poisson's ratio, $v$, for the casing material were chosen as follows:

$E=72,000 \mathrm{MPa}, \quad v=0.33$

The original flow stress equation for the casing material was determined from the tensile test data:

$\bar{\sigma}(\mathrm{MPa})=745.39 \bar{\varepsilon}^{0.113}$

The hardness of the casing was measured using a Micro Vickers Hardness tester. Four strips of $\sim 2 \mathrm{~mm}$ thickness were cut from three casings (Fig. 2). The hardness measurements were noted along the length of these strips with more readings concentrated in the crimped region (Region $\mathrm{AB}$ ). Due to proprietary reasons, details on the hardness distribution are not disclosed. Using the maximum and minimum range of the hardness distribution, the maximum and minimum flow stresses were estimated i.e. $\bar{\sigma}_{\max }$ and $\bar{\sigma}_{\min }$, respectively.

The hardness values in Region $\mathrm{AB}$ were found to range between $1618.09 \mathrm{MPa}\left(165 \mathrm{kgf} / \mathrm{mm}^{2}\right)$ and $1323.89 \mathrm{MPa}$ $\left(135 \mathrm{kgf} / \mathrm{mm}^{2}\right)$. These two values of hardness were used to obtain the minimum and maximum flow stress curves for the tube/casing material (Fig. 3). The details of the estimation

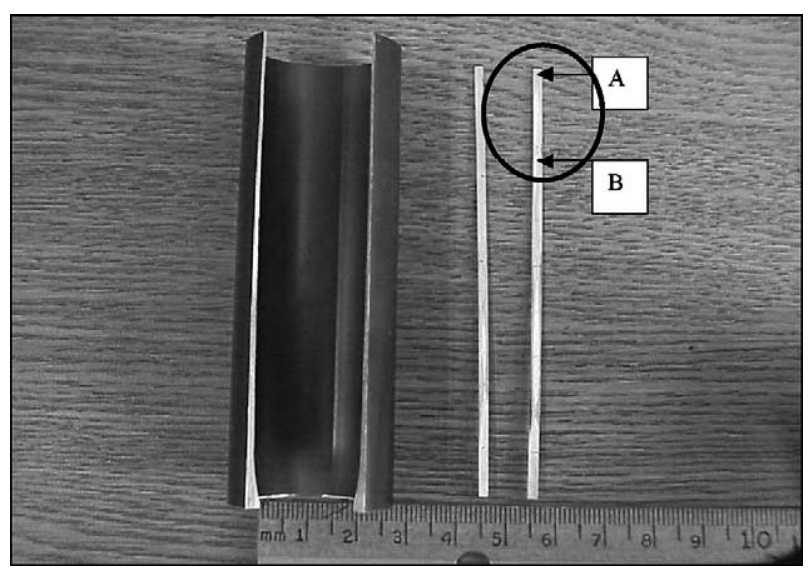

Fig. 2. Tube with two of the strips cut from it for hardness measurement [4]. 


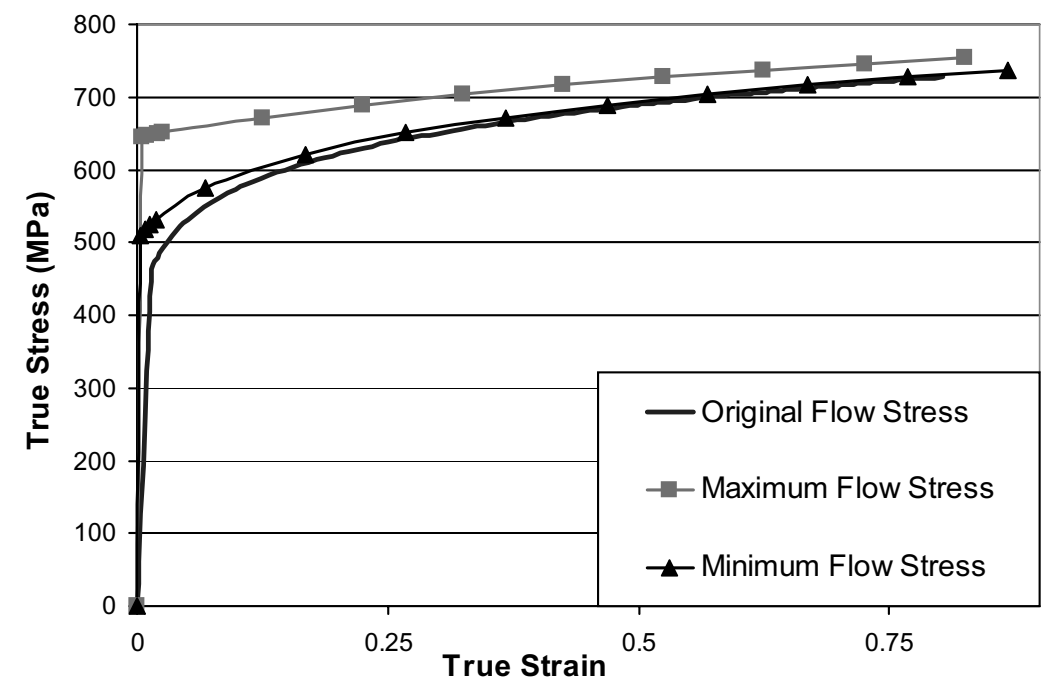

Fig. 3. Maximum and minimum flow stress curves compared with the original flow stress curve for the casing material [2].

of the flow stress from the hardness of the material can be found in Ref. [5].

\section{Press fitting of the rod into the casing}

The press fitting operation is the primary stage of the hydraulic crimping process. In this operation, the steel $\mathrm{rod} / \mathrm{bullet}$ is first inserted into the casing up to the upper groove. A sealant is applied on the upper groove before the bullet is completely inserted into the casing. This helps to prevent any atmospheric contamination of the contents of the casing during further processing and storage.

The rod/bullet has to be press fitted inside the casing since there exists an interference fit between the two. The interference between the bullet and casing affects the stress distribution in the casing prior to the crimping operation. This in turn influences the crimp quality as determined by the force required to pull the bullet out of the casing. The goal was to study the influence of variability of interference fit on the crimp quality caused by errors or tolerances during the manufacturing of the casing and the bullet. Thus, maximum and minimum interference were used in the FE analysis.

Two alignments were chosen for the press fitting process (Fig. 4) to study the effect of the depth to which the rod/bullet is inserted on the crimping and pullout force. This consider-

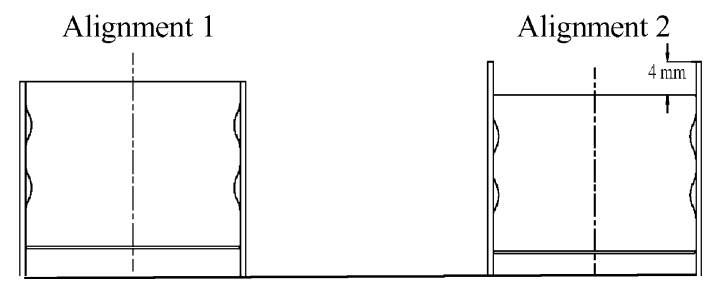

Fig. 4. The two alignments chosen for the simulations of the press fitting operation. ation addresses the misalignment errors that may occur during the press fitting stage. The circumferential stress in the casing at the end of press fitting was noted along the length of the casing and predictions on the crimping quality and pullout force were made based on the observed stress distribution in each case. The shifted flow stress data obtained from the maximum and minimum hardness values discussed earlier was used as the material data for the simulations (Fig. 3).

The FE model of the casing and rod/bullet is shown in Fig. 5. The casing was modeled elastic-plastic whereas the rod was assumed to be rigid. Due to radial symmetry the model was axisymmetric with quadrilateral elements. The crimped region was assigned a finer mesh than the rest of the casing. The casing was constrained from moving in the $Z$ direction since this emulates the practical conditions.

Two alignments (Fig. 4) were chosen for the simulation of the press fitting stage. First the simulations were run until alignment 1 and then run further to obtain the second alignment. Due to the absence of a lubricant during the press

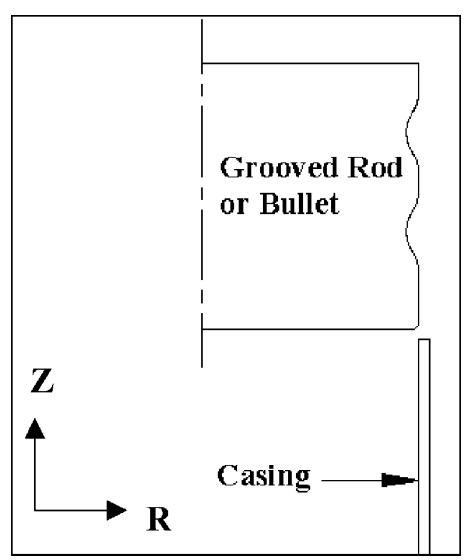

Fig. 5. Finite element (FE) model for simulating the press fitting process. 


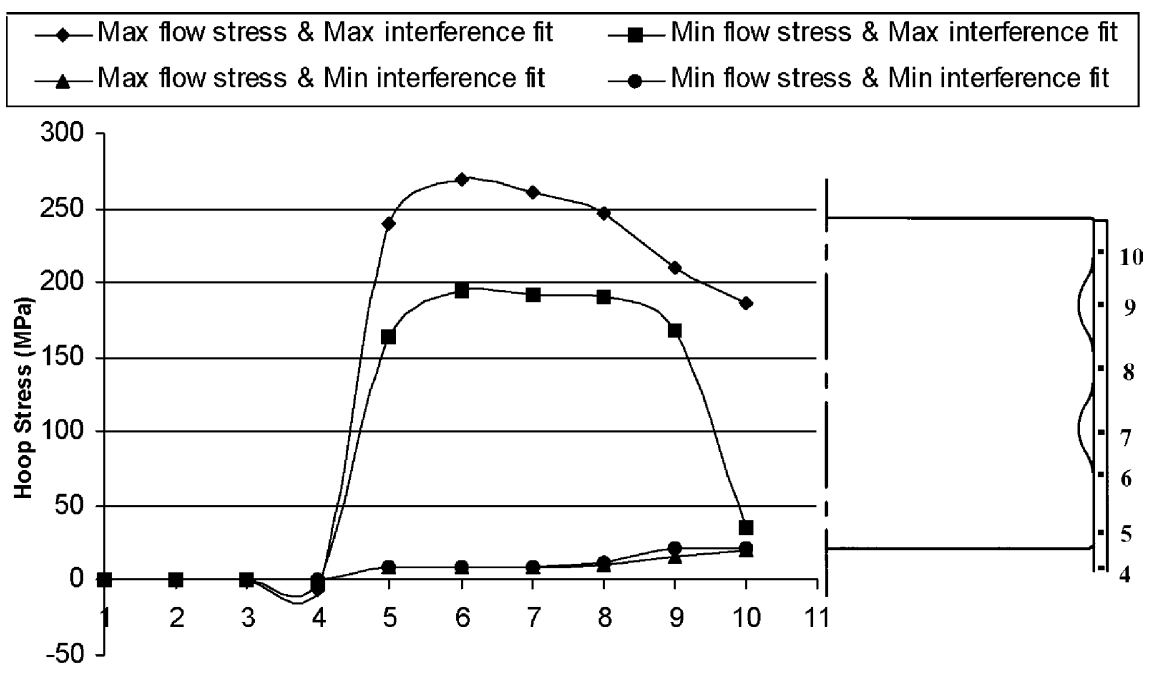

Points chosen from the bottom to the top of the casing

Fig. 6. Comparison of hoop stress for alignment 1 with friction coefficient $\mu=0.45$.

fitting stage two relatively high coefficients of friction $(\mu)$ were used e.g. 0.2 and 0.45 . The effect of the variation in the alignments and friction on the pullout force was studied by comparing the hoop or circumferential stress distribution at the end of the press fitting operation.

The hoop stress obtained at the end of crimping was plotted for both the alignments, along the length of the casing for 10 points starting from the bottom of the casing to the top. More points were selected in the region to be crimped. The stress in the bottom portion of the casing was expected to be negligible, which was confirmed by the values of stress in this region (Figs. 6 and 7). The following observations were made from the graphs of hoop stress:

(i) For a friction coefficient of 0.45 , the cases with maximum interference fit exhibited maximum (tensile) hoop stress in the region of the casing in contact with the rod (Figs. 6 and 7). For a coefficient of friction of $\mu=0.2$, the values of hoop stress were slightly lower than those seen for $\mu=0.45$.

(ii) The value of the hoop stress reduced towards the mouth/top of the casing as a result of the springback of the casing after the rod/bullet has been pushed in.

(iii) For the cases of minimum interference the stresses in the casing were very small.

(iv) The hoop stress values for alignment 2 were slightly higher than those for alignment 1 (Figs. 6 and 7).

Comparing the values of stress for both the alignments it was observed that alignment within the range investigated had very little effect on the induced stress in the casing during press fitting.

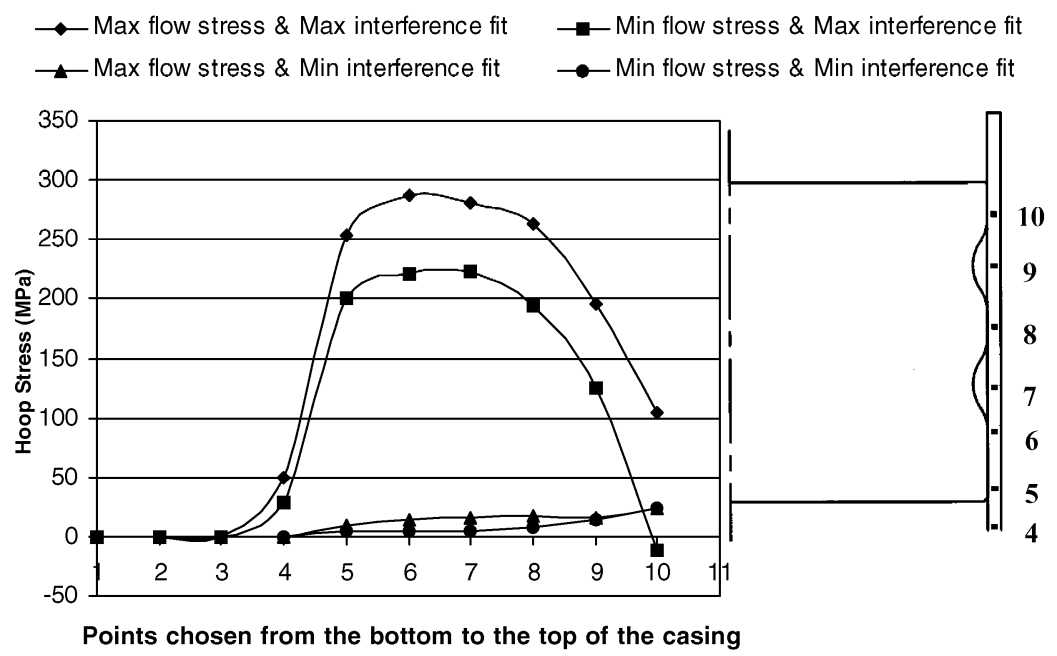

Fig. 7. Comparison of hoop stress for alignment 2 at friction coefficient $\mu=0.45$. 


\section{Simulation of the crimping process}

The press fitted rod-casing assembly is crimped using a polyurethane/rubber crimper that is actuated externally with hydraulic pressure. The process takes approximately $0.75 \mathrm{~s}$ with the pressure increasing from 0 to $162.026 \mathrm{MPa}$ in $0.1 \mathrm{~s}$. The last step from the press fitting simulation for each case was used as the first step for the crimping simulations. The FE model for the crimping simulation is shown in Fig. 9 with the rubber crimper. The process parameters used for the simulations were the same as in the press fitting stage. The rubber/polyurethane crimper (Fig. 8) was modeled as a plastic object using the material properties obtained from the compression test (Fig. 9).

The simulations were run using a pressure boundary condition on the outer surface of the crimper (Fig. 10). The strains at the end of crimping were noted for both the alignments as a measure of the crimp quality (Fig. 11).

The effective strain obtained at the end of crimping was plotted for both the alignments along the length of the casing for 10 points starting from the middle of the casing to the

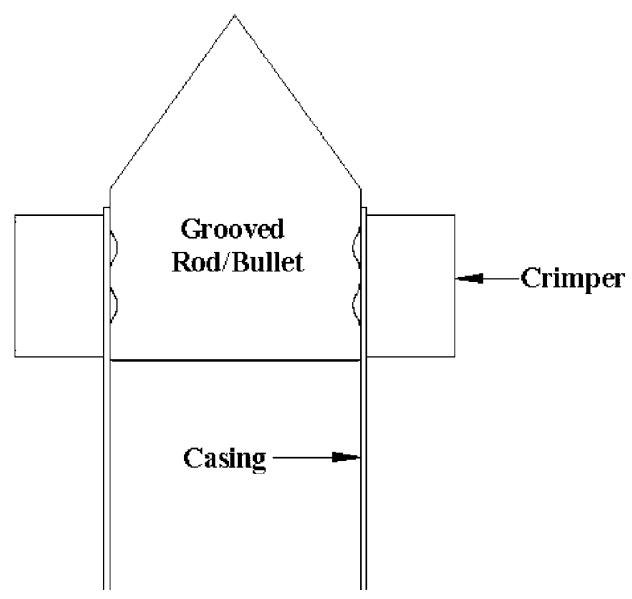

Fig. 8. FE model of the crimping operation.

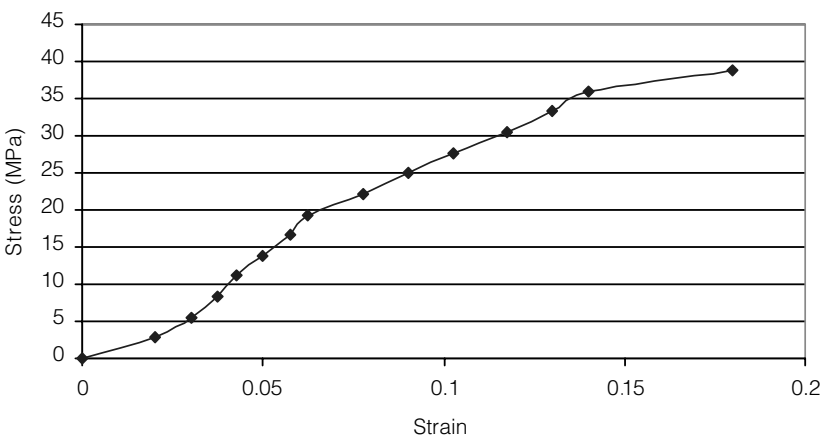

Fig. 9. True stress-strain curve for the polyurethane/rubber crimper material obtained from the compression test.

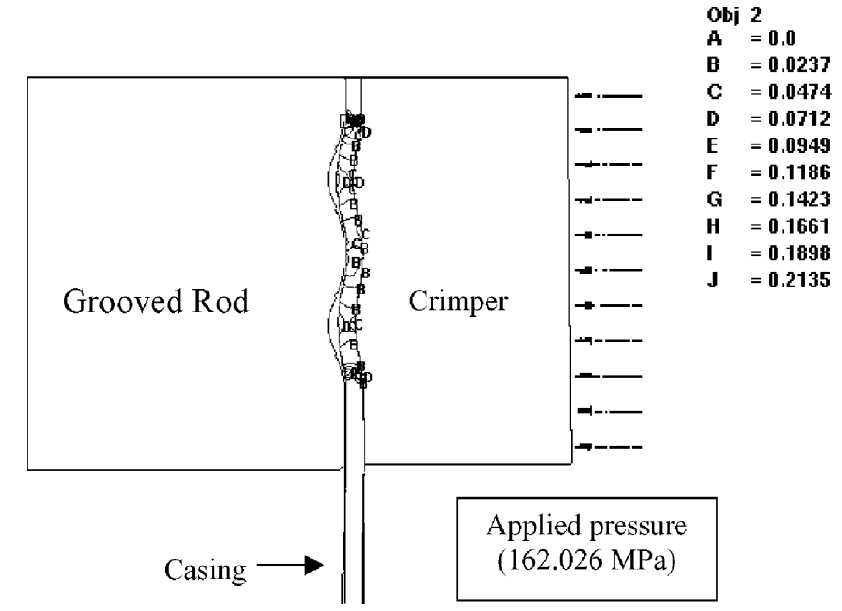

Fig. 10. Effective strain obtained at the end of crimping.

top. More points were selected in the region to be crimped e.g. points $3-10$. The strain in the portion of the casing in contact with the flat region of the rod was expected to be negligible, which was confirmed by the values of strain in this region (Figs. 11 and 12). Maximum strains were observed in the vicinity of the grooves in the rod. For a friction coefficient of 0.45 , the cases with minimum flow stress

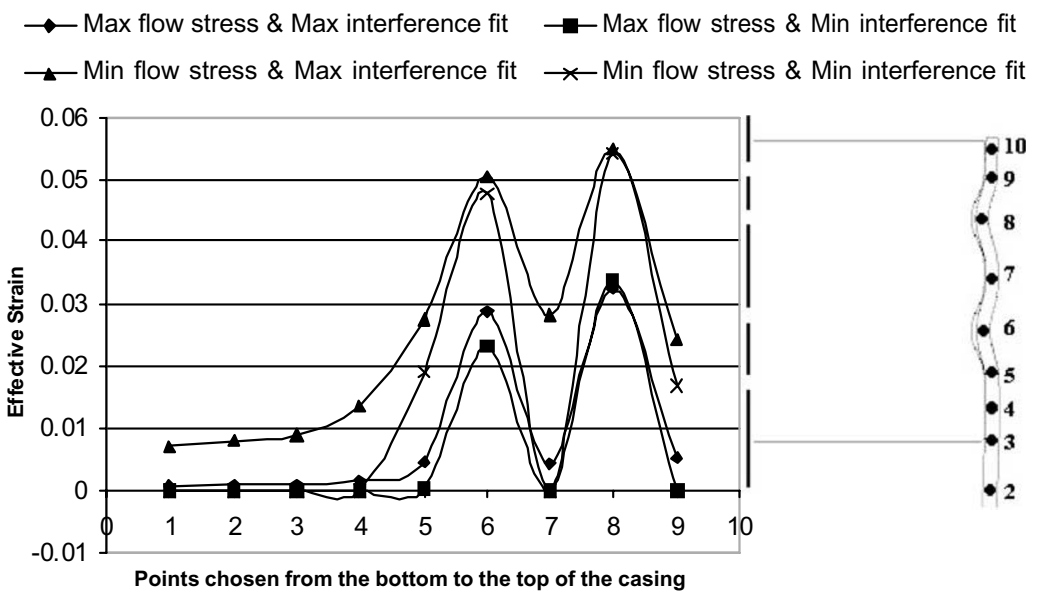

Fig. 11. Effective strains at the end of crimping for alignment 1 and friction coefficient $\mu=0.45$. 


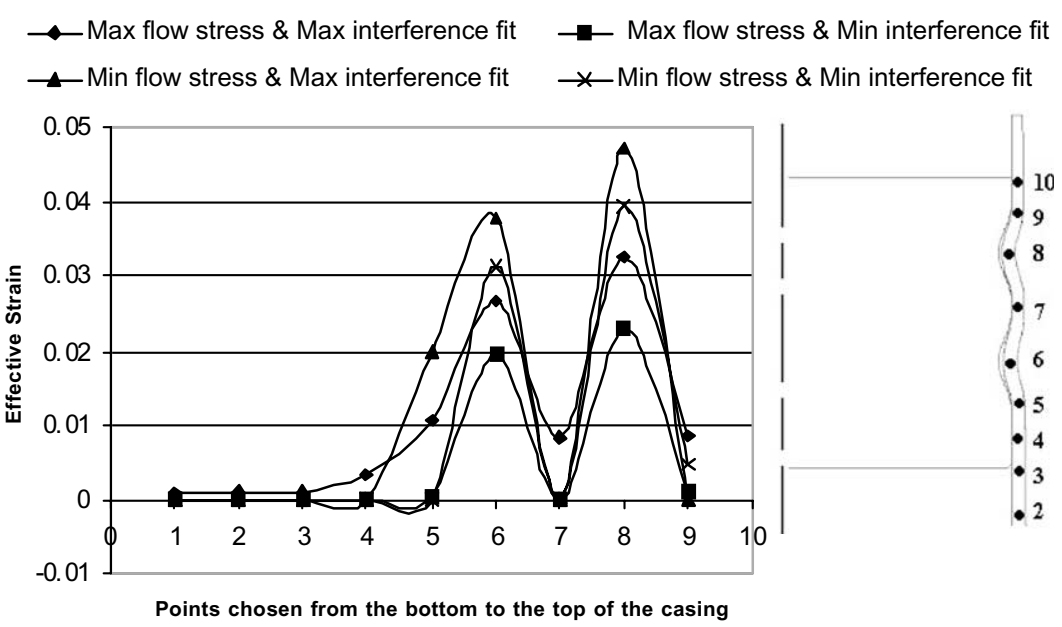

Fig. 12. Effective strains at the end of crimping for alignment 2 and friction coefficient $\mu=0.45$.

exhibited maximum strains as was expected. The effective strains for friction coefficient 0.2 showed the same trends as that of 0.45 with the values of strains being larger than those for the higher coefficient of friction $(\mu=0.45)$. The cases with the higher strains in the tube were expected to give higher pullout forces. The values of strains obtained for alignment 2 (Fig. 12) were slightly smaller than those for alignment 1 (Fig. 11).

\section{Rod pullout test}

The quality of the crimps was evaluated based on the simulations of the rod/bullet pullout test for each of the combinations of process parameters. The last step from the crimping simulation was used to simulate the bullet pullout by giving movement to the bullet in the positive $Z$ direction. The load stroke curve provided the value of the force required to pull the rod/bullet out of the casing. During pullout testing, the bullet is held within a collar, which covers the crimped region and restricts the movement of the casing in this region in the $R$ direction (Fig. 13). The axisymmetric FE model used for the simulations is shown in Fig. 14.

For the two alignments selected (Fig. 4), when the pullout forces were compared for maximum and minimum flow stress (Figs. 15 and 16), the following observations were made:

(i) A higher coefficient friction resulted in higher pullout force. This behavior was independent of the flow stress or interference fit used.

(ii) The cases with minimum interference fit resulted in lower hoop stresses at the end of press fitting. This resulted in better crimping and hence, higher pullout values.

(iii) The trend for the pullout forces was the same for minimum flow stress. However, the pullout force values

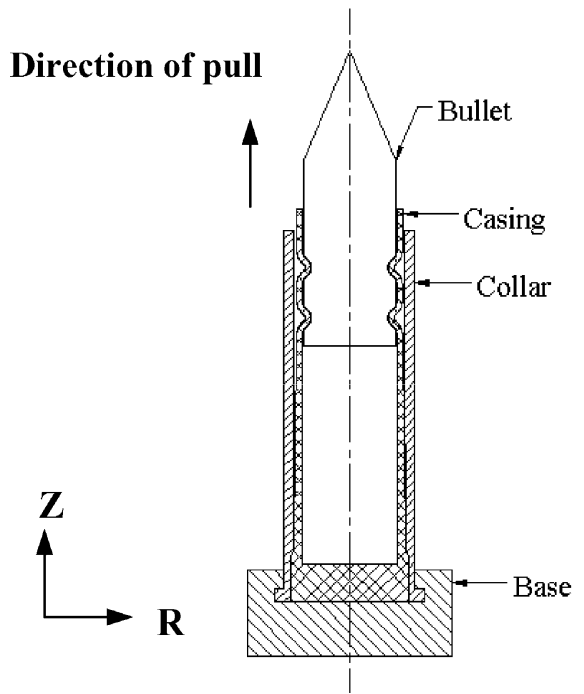

Fig. 13. Rod pullout test setup.

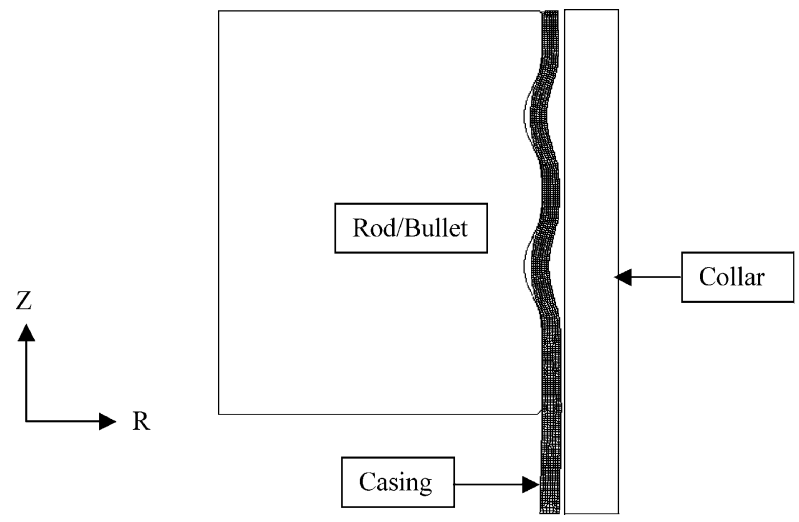

Fig. 14. FE model for the rod pullout test. 


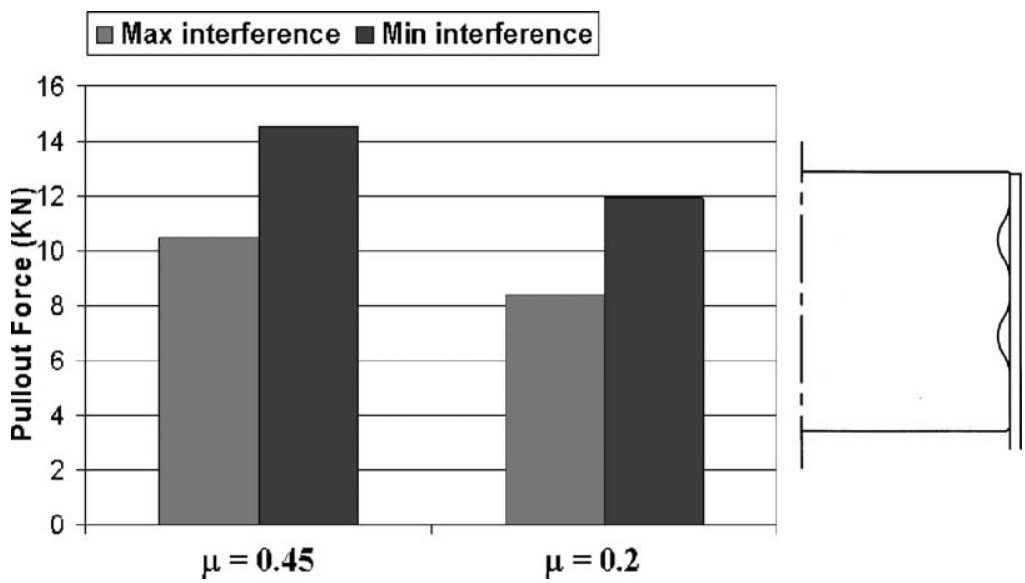

Fig. 15. Comparison of pullout forces for maximum flow stress for alignment 1 for different friction coefficients $(\mu)$ and interference fits.

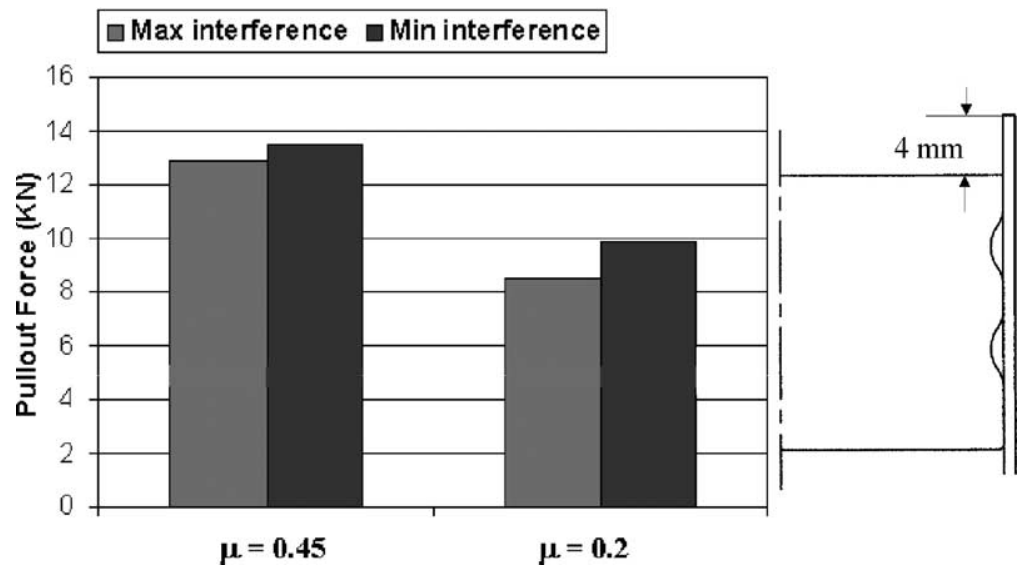

Fig. 16. Comparison of pullout forces for maximum flow stress for alignment 2 for different friction coefficients $(\mu)$ and interference fits.

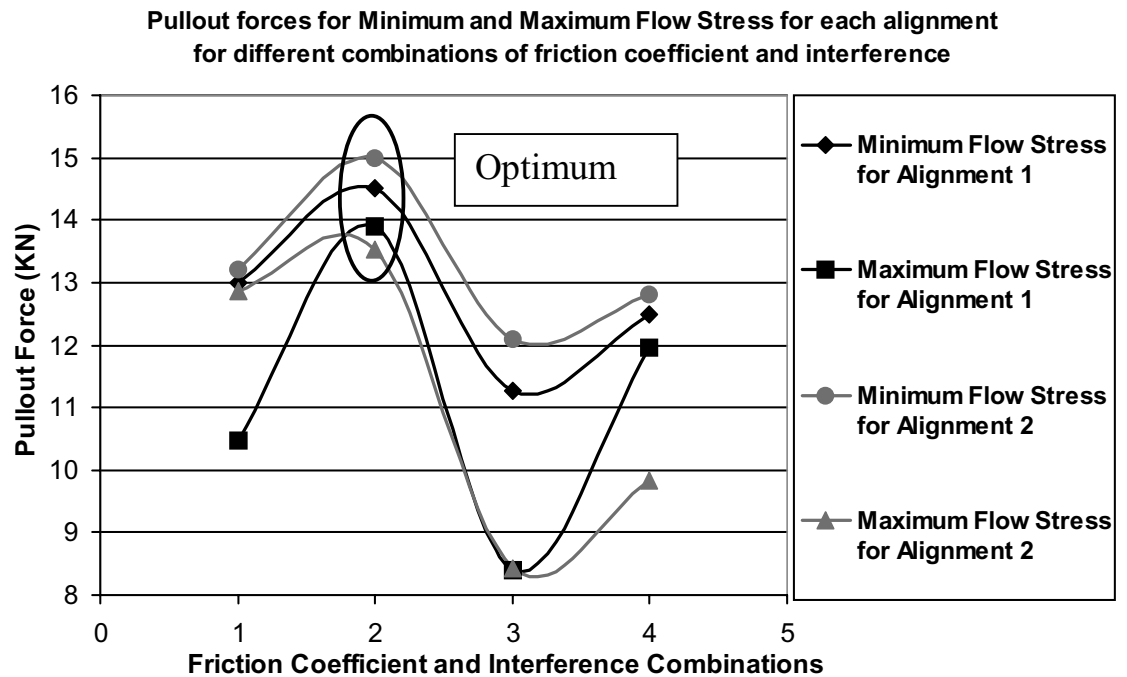

Fig. 17. Optimum process parameters (high pullout forces) for the rod crimping process. 


\begin{tabular}{|c|c|}
\hline $\begin{array}{c}\text { Combination } \\
\text { Number }\end{array}$ & $\begin{array}{c}\text { Friction Coefficient }(\mu) \text { and } \\
\text { Interference Fit }\end{array}$ \\
\hline 1 & $\mu=0.45 ;$ Maximum Interference Fit \\
\hline $2^{*}$ & $\mu=0.45$; Minimum Interference Fit \\
\hline 3 & $\mu=0.2 ;$ Maximum Interference Fit \\
\hline 4 & $\mu=0.2 ;$ Minimum Interference Fit \\
\hline
\end{tabular}

Fig. 18. Process conditions for optimum crimping operation.

observed were higher than those observed for maximum flow stress since minimum flow stress resulted in higher strains in crimping and thus, a greater force being required to pull the rod/bullet out of the casing.

The pullout force results are summarized in Fig. 17, which gives a plot of the pullout force values for maximum and minimum flow stress for the two alignments for different combinations of friction coefficient and interference fit.

Higher pullout forces were observed when the flow stress of the casing was at the minimum value and the friction coefficient was maximum i.e. 0.45 . The maximum value of pullout force was observed to be approximately $15 \mathrm{kN}$ (approximately $3.37 \mathrm{klbf}$ ). The cases with maximum interference fit and minimum coefficient of friction exhibit lowest pullout force values (Fig. 17). The pullout values obtained were close to the experimentally obtained average value of $11.15 \mathrm{kN}(2.507 \mathrm{klbf})$, provided by the manufacturer.

The optimum conditions seen in Fig. 17 are summarized in Fig. 18.

\section{Conclusions}

This study has demonstrated that the variability in: (a) interface friction conditions, (b) material properties, (c) rod-casing alignment of the assembled components and (d) errors/tolerances due to manufacturing can significantly affect the quality of the crimp. In the manufacturing process of the bullets, this translates into variation in the muzzle velocity and accuracy of the rod.

The major conclusions drawn from the study of the hydraulic crimping operation are:
1. The hoop stress distribution at the end of press fitting indicated higher stresses for maximum interference fit than for minimum interference fit. Thus, lower pullout forces were predicted for the cases with maximum interference fit.

2. The effective strains observed at the end of the rod crimping process lead to the prediction that the cases with minimum flow stress and higher coefficient of friction would result in higher pullout values since the strains observed were higher than those for the cases with maximum flow stress.

3. It was observed from the rod pullout values for the two alignments that the combination of minimum flow stress, minimum interference fit and maximum friction yielded the maximum pullout force values.

4. Under the conditions used in this study it was found that the pullout forces vary from approximately $9-15 \mathrm{kN}$. This is a significant variation, which may have a large impact on the quality requirements of a crimp-based assembly.

\section{Acknowledgements}

The authors wish to thank the Alliant Ammunition and Powder Company, Radford Army Ammunition Plant, VA, USA for funding this study.

\section{References}

[1] J.P. Varis, The suitability of round clinching tools for high strength structural steel, Thin Walled Struct. 40 (2002) 225-238.

[2] M. Shirgaokar, G. Ngaile, T. Altan, Stress Analysis and Evaluation of a Bullet Crimping Process of an LW30 Round Report No. ERC/NSM-01-31-B, 2002.

[3] S. Jayaraman, G.T. Hahn, W.C. Oliver, C.A. Rubin, P.C. Bastias, Determination of monotonic stress-strain curve of hard materials from ultra-low-load indentation tests, Int. J. Solid Struct. 35 (1998) 364382.

[4] H. Cho, S. Saxena, Stress analysis and Evaluation of a Bullet Crimping Process, Progress Report I, Report No. ERC/NSM-00-48, 2000.

[5] M. Shirgaokar, H. Cho, G. Ngaile, T. Altan, Optimization of mechanical crimping to assemble tubular components 146 (2004) 3543. 